ORIGINAL ARTICLE

\title{
A randomised, controlled trial of once daily and multi-dose daily gentamicin in young Kenyan infants
}

\author{
M English, S Mohammed, A Ross, S Ndirangu, G Kokwaro, F Shann, K Marsh
}

Arch Dis Child 2004;89:665-669. doi: 10.1136/adc.2003.032284

See end of article for authors' affiliations

....................

Correspondence to: Dr M English, CGMR-C, KEMRI/Wellcome Trust Research Laboratories, PO Box 230, Kilifi, Kenya; menglish@wtnairobi. mimcom.net

Accepted 7 October 2003

\begin{abstract}
Aims: To test the suitability of a simple once daily (OD) gentamicin regimen for use in young infants where routine therapeutic drug monitoring is not possible.

Methods: In an open, randomised, controlled trial, infants with suspected severe sepsis admitted to a Kenyan, rural district hospital received a novel, OD gentamicin regimen or routine multi-dose (MD) regimens.

Results: A total of 297 infants (over $40 \% \leqslant 7$ days) were randomised per protocol; 292 contributed at least some data for analysis of pharmacological endpoints. One hour after the first dose, $5 \%(7 / 136)$ and $28 \%(35 / 123)$ of infants in OD and MD arms respectively had plasma gentamicin concentrations $<4 \mu \mathrm{g} /$ $\mathrm{ml}$ (a surrogate of treatment inadequacy). Geometric mean gentamicin concentrations at this time were $9.0 \mu \mathrm{g} / \mathrm{ml}(95 \% \mathrm{Cl} 8.3$ to 9.9$)$ and $4.7 \mu \mathrm{g} / \mathrm{ml}(95 \% \mathrm{Cl} 4.2$ to 5.3$)$ respectively. By the fourth day, predose concentrations $\geqslant 2 \mu \mathrm{g} / \mathrm{ml}$ (a surrogate of potential treatment toxicity) were found in $6 \%(5 / 89)$ and $24 \%(21 / 86)$ of infants respectively. Mortality was similar in both groups and clinically insignificant, although potential gentamicin induced renal toxicity was observed in $<2 \%$ infants.

Conclusions: A "two, four, six, eight" OD gentamicin regime, appropriate for premature infants and those in the first days and weeks of life, seems a suitable, safe prescribing guide in resource poor settings.
\end{abstract}

$\mathrm{n}$ adult patients there has been a substantial shift in clinical practice towards the use of gentamicin once daily over the past decade. ${ }^{1}$ The empiric evidence underlying this change in practice has been summarised in several metaanalyses $^{2-4}$ and reviews. ${ }^{5}$ However, although recognised as a problem, ${ }^{6}{ }^{7}$ there are few comparable efficacy data on the use of once daily gentamicin regimes in the neonatal and early infant period despite its common use for empiric treatment of severe infection in this age group. Until 2001 published data were only available from 71 infants treated in the first week of life ${ }^{8}$ with data on a further 41 infants of a least $2500 \mathrm{~g}$ in weight reported recently. ${ }^{9}$ While these largely pharmacokinetic data ${ }^{10-13}$ tend to support once daily gentamicin use, reinforcing the recent World Health Organisation (WHO) endorsement of this approach, ${ }^{14}$ there is little practical guidance on how such a regime might be operationalised in resource poor settings. Yet gentamicin administration in the newborn period is far from straightforward. Early studies suggest dose adjustment on the basis of both gestation and postnatal age,,$^{15-18}$ and use of a "loading dose" is recommended. ${ }^{19}$ Extrapolation of the results of detailed, developed country pharmacokinetic studies to resource poor settings may also be difficult. In one study where it is explicitly reported, almost $20 \%$ of infants had dose adjustments made during a study of once daily treatment as a result of drug concentration results. ${ }^{11}$ In other studies it seems likely that there were even higher rates of real time dose adjustment if "abnormal results" were acted on. ${ }^{13}$

For those practicing in resource poor settings the picture therefore remains somewhat confused. In Kenya, current guidelines advise a multi-dose gentamicin regime that takes into account both the presence of prematurity and postnatal age, ${ }^{20}$ while the new WHO guidelines refer only to infants over $3 \mathrm{~kg}$ in weight and suggest dose adjustment for age less than 1 week only. ${ }^{14}$ The practical problems faced when using gentamicin in resource poor countries include an absence of accurate gestational age assessment, the inability to assess renal function biochemically, and the absence of therapeutic drug monitoring. Furthermore, on wards where staff to patient ratios are very low, it is often only practical to administer drugs at fixed times in the day rather than at individually optimal times. Since case fatality rates are high among sick young infants, and as they may be at higher risk of drug related toxicity, we have investigated the use of a novel once daily regimen. We compared its performance, using pharmacological outcome measures, to the current multi-dose regimen used in Kenya, in a situation that closely mimics operational conditions.

\section{METHODS}

The study was undertaken at Kilifi District Hospital on the Kenyan Coast, the main government inpatient facility for a drainage population of at least 200000 people. Interventions available for the inpatient management of sick infants include oxygen, antibiotics, intravenous fluids (not parenteral nutrition), nasogastric feeding of expressed breast milk, phototherapy, and exchange transfusion. During the period of the study an incubator was not routinely available. Sick infants are investigated according to a standard protocol with a full blood count, blood culture, plasma electrolytes, creatinine (Beckman Instruments, USA), and glucose with bilirubin and lumbar puncture performed when appropriate. Empiric management of suspected severe infection is with gentamicin and one of benzylpenicillin, ampicillin, or cloxacillin, the choice being at the discretion of the admitting clinician. Drugs are given at four fixed times daily. Once daily (OD) drugs are given routinely at 0900 , twice daily drugs at 0900 and 2100 , and thrice daily drugs at 0900,1500 , and 2100 . Except in rare instances infusion pumps are unavailable. Gentamicin is therefore routinely given intramuscularly.

The once daily gentamicin regimen was designed to accommodate the practicalities of our setting and to take account of the following assumptions: (1) if rapid bacterial killing is desirable, then a high initial dose with a high initial

Abbreviations: $M D$, multi-dose; $O D$, once daily 
serum peak gentamicin concentration is required; ${ }^{21}(2)$ dose adjustment is required in the first week of postnatal life; (3) dose adjustment for prematurity and low weight for gestational age infants is necessary, ${ }^{15}{ }^{16}$ and (4) increased trough (pre-dose) concentrations of gentamicin increase the risk of toxicity. As gestational age determination from history is unreliable and estimation from physical features is impractical, weight was used as a proxy measure. Table 1 describes the trial regimens. It should be noted that all children in the OD arm received a first dose of $8 \mathrm{mg} / \mathrm{kg}$ before continuing routine treatment with an age and weight specific dose. In practice the OD regimen meant that children received gentamicin only once per calendar day, although this meant children admitted at 0100 or 2300 would both receive their second doses at 0900 the following day, dose intervals of 32 hours and 10 hours respectively, before starting true 24 hour dosing.

Approval for the study was obtained from the national Kenyan Ethical Committee and it ran from August 2000 to April 2001. All children less than 3 months of age admitted to the ward until January 2001 and less than 2 months of age from February 2001 were screened for enrolment in the study using a computerised questionnaire. In January 2001 on the basis of local bacteriological surveillance data (J Berkley, unpublished), the local management guidelines were changed, limiting the use of gentamicin as empiric treatment to infants less than 2 months of age. Children were excluded if: weight was $<1 \mathrm{~kg}$, there was a primary diagnosis of tetanus, gentamicin had been administered previously, there were major life threatening congenital malformations, there was a history of anuria for 24 hours, or the admission creatinine was outside a defined acceptable range (table 1). The parents of children who remained eligible were given information about the study in their local language by a trained project assistant and consent was sought for enrolment. Confirming that consent had been obtained on the questionnaire triggered computerised randomisation and regimen allocation. Thus concealment was ensured although the study was not blinded.

Two batches of gentamicin, from different manufacturers, were used in sequence during the trial and were supplied by a pharmaceutical agency (Mission for Essential Drugs and Supplies) used by government and other hospitals. Vials containing $40 \mathrm{mg} / \mathrm{ml}$ of gentamicin as the sulphate were used. Although not ideal for use in infants, this formulation is the most commonly available in practice. Venous or capillary blood samples (volume $0.5 \mathrm{ml}$ ) were taken from enrolled infants one hour after the first $\operatorname{dose}^{22}$ (the 1 hour sample), before the second dose in children receiving once a day therapy (the day 1 sample), one hour after the morning dose on the third day of therapy (the 72 hour sample), and immediately before the morning dose on the fourth day of therapy (the 96 hour sample). Serum was frozen and stored and gentamicin assays were performed in batches using an Abbott TDx FLx auto-analyser (Abbott Diagnostics, IL, USA). Intra-assay quality control using high, medium, and low level standards showed coefficients of variation of $<3.6 \%$. A repeat creatinine measurement was obtained from the 96 hour sample. The parents of infants prescribed prolonged treatment were asked if further pre-dose samples on the eighth day of therapy could be taken for gentamicin assay and measurement of creatinine.

\section{Sample size estimation and statistical analysis}

The trial regimens were to be compared on the basis of two main endpoints: the proportion having a serum gentamicin concentration $>4 \mu \mathrm{g} / \mathrm{ml}$ in the 1 hour sample and the proportion of infants with a serum gentamicin concentration $\geqslant 2 \mu \mathrm{g} / \mathrm{ml}$ in the 96 hour sample. In addition the proportion of children with a serum gentamicin concentration $>4 \mu \mathrm{g} / \mathrm{ml}$ in the 72 hour sample and the proportion having a significant increase in plasma creatinine at 96 hours were to be estimated for each group. The latter was defined as an increase by more than $50 \%$ in plasma creatinine from baseline that also resulted in a value outside the pre-defined acceptable range ${ }^{23} 24$ (table 1). The study was not designed to compare differences in mortality. A total sample size of 306 infants, assuming a $40 \%$ loss rate by 96 hours (due to death and discharge), was calculated to be sufficient to show a difference of $30 \%{ }^{15}$ versus $10 \%$ in the proportion with a high 96 hour concentration in the multi-dose and once daily groups respectively, with power $90 \%$ and significance $5 \%$. This sample size would be more than sufficient to show a difference in inadequate peak concentrations at 1 hour of $50 \%{ }^{25}$ versus $25 \%$ in multi-dose and once daily groups respectively with the same power and significance.

During the study all data were entered in Foxpro 2.1 and other than the study registration and randomisation questionnaire (that was entered directly at admission) all data were double entered and verified. Two tailed Fisher's exact tests and $t$ tests were used when comparing group proportions or means respectively. Skewed continuous data were $\log$ transformed where appropriate prior to analysis. The possible effect of gentamicin batch differences on the outcomes low peak concentrations at 1 and 72 hours and high trough concentrations at 96 hours was assessed using logistic regression with adjustment for dosage group, admission creatinine, regimen, and sex. Analyses were conducted with STATA 6 (Stata Corporation, USA).

\section{RESULTS}

Within the study period 566 infants of an age appropriate for the study were admitted to the hospital. Figure 1 illustrates recruitment from this total population and progress of

Table 1 Gentamicin dosing regimen and defined acceptable range for creatinine

\begin{tabular}{|c|c|c|c|}
\hline Regimen & Age & Weight $<2.0 \mathrm{~kg}$ & Weight $\geqslant 2.0 \mathrm{~kg}$ \\
\hline Once daily $†$ & $\leqslant 7$ days* & $2 \mathrm{mg} / \mathrm{kg}$ (group A.1) & $4 \mathrm{mg} / \mathrm{kg}$ (group B.1) \\
\hline Once daily† & $>7$ days & $4 \mathrm{mg} / \mathrm{kg}$ (group C.1) & $6 \mathrm{mg} / \mathrm{kg}$ (group D.1) \\
\hline Multi-dose & $\leqslant 7$ days* & $2.5 \mathrm{mg} / \mathrm{kg}$ bd (group A. 2) & $2.5 \mathrm{mg} / \mathrm{kg}$ bd (group B.2) \\
\hline Multi-dose & $>7$ days & $2.5 \mathrm{mg} / \mathrm{kg}$ bd (group C.2) & $2.5 \mathrm{mg} / \mathrm{kg}$ tds (group D.2) \\
\hline \multicolumn{4}{|c|}{ Upper limit for creatinine $\mu \mathrm{mol} / \mathrm{I}^{2324}$} \\
\hline Age $0-2$ days & & 190 & 140 \\
\hline Age 3-7 days & & 120 & 110 \\
\hline Age $8-14$ days & & 100 & 90 \\
\hline Age $14+$ days & & 90 & 90 \\
\hline
\end{tabular}

*On the eighth day of life it was recommended that dosage was stepped up where appropriate to the dose indicated for an 8 day old infant using the regime allocated at randomisation. $\dagger$ All children in the once daily group received an initial dose of $8 \mathrm{mg} / \mathrm{kg}$ before continuing with routine dosing adjusted for weight and age. 
infants in the study. Among the 297 infants enrolled as per protocol mortality was $13 \%$ although among those aged $\leqslant 7$ days mortality was $24 \%$. Table 2 presents basic demographic indices, baseline laboratory results, and process indices for the two groups. Five children were administered an incorrect first dose and had no blood samples taken. On three occasions $(3 \mathrm{MD})$ the time to the 1 hour peak sample was outside our planned optimal $\operatorname{range}^{22}(45-240$ minutes after dose administration), while this occurred on 25 occasions (15 in OD group) for the 72 hour peak sample. Restricting analyses to samples collected within the optimal range did not make any clinical or statistical difference to the results or their interpretation. An intention to treat analysis including all available data is therefore presented. Five gentamicin concentrations at 1 hour and one at 72 hours were $>10 \mu \mathrm{g} / \mathrm{ml}$ but low sample volume precluded exact measurement. These data are included in comparisons of proportions only.

Peak gentamicin concentrations 1 hour after the first dose were significantly higher in the infants treated once daily (table 3). Trough concentrations at 96 hours were lower in the OD treated infants. This resulted in a considerable difference in the proportions of children with a trough concentration $<2 \mu \mathrm{g} / \mathrm{l}$ in the OD and MD groups, although this difference disappeared if a more stringent criterion of an acceptable trough concentration $\left(<1 \mu \mathrm{g} / \mathrm{l}^{26}\right)$ was used for the OD group. The considerable between patient variability in gentamicin concentrations during treatment is illustrated by the broad range of measured peak concentrations at 1 hour and at 72 hours (table 3 ). Some of this variability may be explained by drug administration errors or variable absorption after intramuscular injection in small, sick infants. Logistic regression analysis controlling for age/weight group membership, admission creatinine, drug batch received, and the allocated regimen confirmed the strong association of the OD regime with an adequate gentamicin concentration at 1 hour (OR 7.2, 95\% CI 2.6 to 19.8) and absence of an increased trough concentration at 96 hours (OR 7.5, 95\% CI 2.4 to 24.0). Drug batch was not associated with any outcome. Only approximately $2 \%$ of infants sampled at

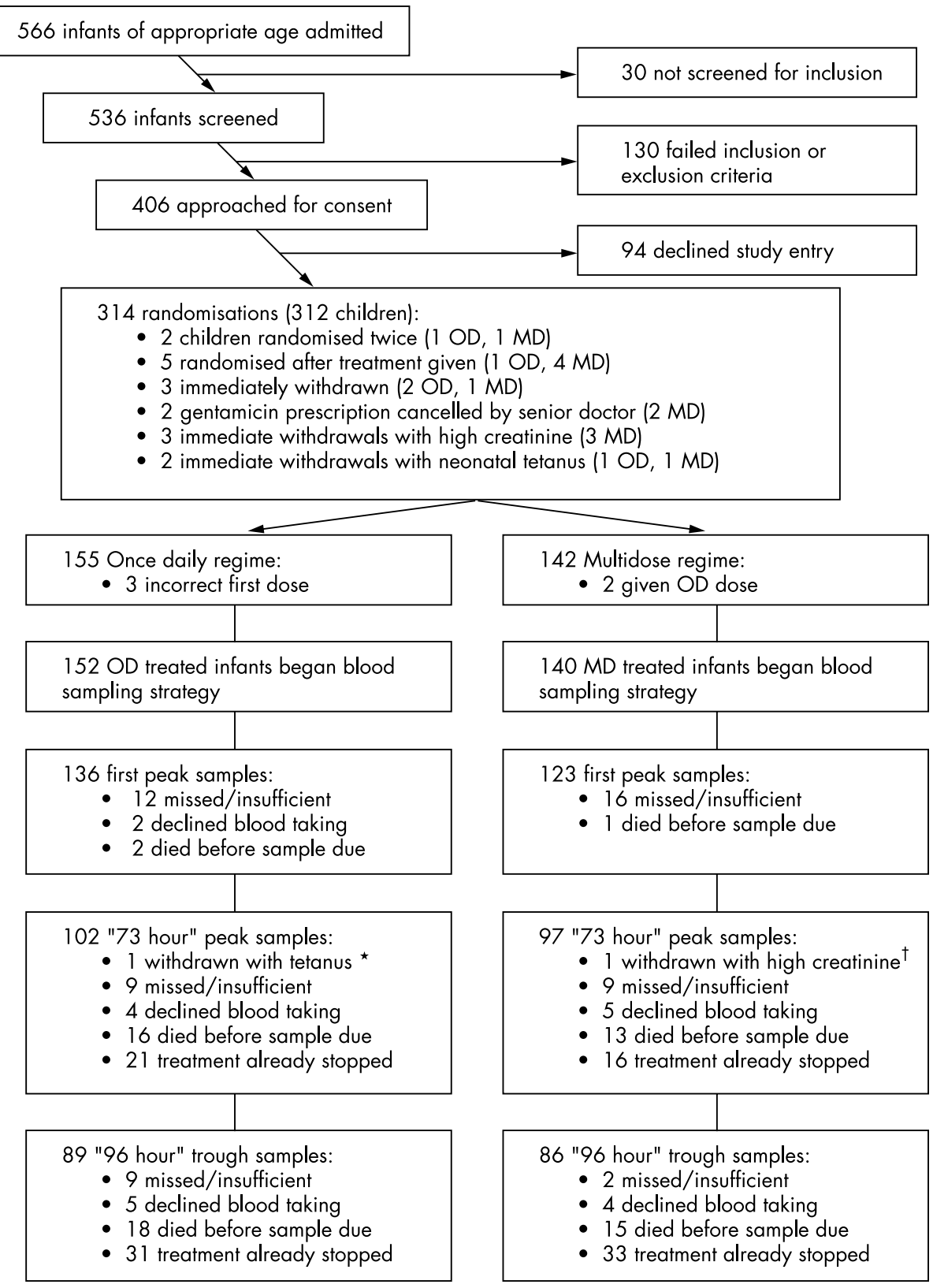

Figure 1 Trial profile. *Diagnosed six hours after admission. †Admission creatinine result obtained late, met exclusion criteria. 
Table 2 Characteristics of children studied

\begin{tabular}{|c|c|c|}
\hline & Once daily regime $(n=155)$ & Multi-dose regimes $(n=142)$ \\
\hline Median age [IQR] (days) & $8[4-30]^{*}$ & $13[4-32]^{*}$ \\
\hline Proportion $\leqslant 7$ days & $76 / 155,49 \%$ & $51 / 142,36 \%$ \\
\hline Mean weight $[95 \% \mathrm{Cl}](\mathrm{kg})$ & $3.0[2.8$ to 3.1$]$ & $3.2[3.0$ to 3.3$]$ \\
\hline Proportion $\leqslant 1.5 \mathrm{~kg}$ & $6 / 155,4 \%$ & $3 / 142,2 \%$ \\
\hline Proportion $>1.5<2.0 \mathrm{~kg}$ & $18 / 155,12 \%$ & $14 / 142,10 \%$ \\
\hline Mean admission creatinine $[95 \% \mathrm{Cl}](\mu \mathrm{mol} / \mathrm{l})$ & $61[56$ to 67$]$ & $57[52$ to 63$]$ \\
\hline Mean admission WBC $[95 \% \mathrm{Cl}]\left(1000 / \mathrm{mm}^{3}\right)$ & $12.5[11.3$ to 13.6$]$ & 13.1 [11.9 to 14.2$]$ \\
\hline Mean admission $\mathrm{Hb}[95 \% \mathrm{Cl}](\mathrm{g} / \mathrm{l})$ & $139[133$ to 144$]$ & $134[128$ to 140$]$ \\
\hline $\begin{array}{l}\text { Median time to } 1 \text { hour, "first peak" sample } \\
\text { [90\% range] (minutes) }\end{array}$ & $65[60-92]$ & $65[60-85]$ \\
\hline $\begin{array}{l}\text { Median time from previous dose to } 72 \text { hour } \\
\text { sample, "peak concentration" [90\% range] } \\
\text { (minutes) }\end{array}$ & $70[60-95]$ & $71[60-90]$ \\
\hline $\begin{array}{l}\text { Median time from previous dose to } 96 \text { hour } \\
\text { sample, "trough concentration" [90\% range] } \\
\text { (minutes) }\end{array}$ & 1419 [1383-1470] & $710[683-750]$ \\
\hline
\end{tabular}

96 hours had any evidence of possible gentamicin associated renal impairment (table 3). Amongst these three children the maximum measured creatinine was $121 \mu \mathrm{mol} / \mathrm{l}$. All survived without clinically apparent renal dysfunction. In 22 cases (seven aged $\leqslant 7$ days) where children were receiving gentamicin for longer than one week, parents consented to repeat pre-dose specimens taken on the eighth day (11 OD, $11 \mathrm{MD})$. One child died; none had a creatinine on the eighth day $>60 \mu \mathrm{mol} / \mathrm{l}$ and none had a pre-dose gentamicin concentration $\geqslant 2 \mu \mathrm{g} / \mathrm{ml}$.

\section{DISCUSSION}

Gentamicin is cheap, widely available and probably a highly effective antibiotic for treating serious infection in young infants in developing countries. ${ }^{27}$ Recent international guidelines suggest it should be used once daily in this age group. ${ }^{14}$ We felt there was a need to provide operational level data to support once daily dosing, if appropriate, to encourage clinicians from resource poor countries with many years of experience with multi-dose gentamicin regimens to change their practice. Producing convincing evidence of the efficacy of once daily gentamicin in sick young infants is however problematic. As is shown by our data, trials using clinically secure endpoints such as mortality would need to be extremely large, and enthusiasm for these is likely to be small given the conclusions of recent meta-analyses in other patient groups. ${ }^{2-4}$ Pharmacological indices are widely used to guide gentamicin dosing where therapeutic drug monitoring is available, but the link between these indices, clinical efficacy, and toxicity are not clear-cut. ${ }^{28}$ This makes pharmacological endpoints imperfect as surrogate markers. However, a convincing case can be made for the need to have safe, high peak gentamicin concentrations, particularly on starting treatment to maximise bacterial killing, and there is good reason to believe that absence of drug free periods predisposes to toxicity. ${ }^{519} 21$ Our results, showing much improved initial gentamicin concentrations (almost a doubling) and of a four-fold reduction in prevalence of raised

\begin{tabular}{|c|c|c|c|}
\hline & Once daily regime & Multi-dose regimes & \\
\hline Died (95\% Cl) & $\begin{array}{l}21 / 155 \\
14 \% \\
(9 \% \text { to } 20 \%)\end{array}$ & $\begin{array}{l}18 / 142 \\
13 \% \\
(8 \% \text { to } 19 \%)\end{array}$ & $p=0.99$ \\
\hline $\begin{array}{l}1 \text { hour peak gentamicin concentration }<4 \mu \mathrm{g} / \mathrm{ml} \\
(95 \% \mathrm{Cl})\end{array}$ & $\begin{array}{l}7 / 136 \\
5 \% \\
(2 \% \text { to } 10 \%)\end{array}$ & $\begin{array}{l}35 / 123 \\
28 \% \\
(21 \% \text { to } 37 \%)\end{array}$ & $p<0.001$ \\
\hline $\begin{array}{l}\text { Geometric mean } 1 \text { hour peak gentamicin } \\
\text { concentration }( \pm 1 \text { SD) }(\mu \mathrm{g} / \mathrm{ml})\end{array}$ & $\begin{array}{l}9.0 \\
(5.3,15.4)\end{array}$ & $\begin{array}{l}4.7 \\
(2.5,9.0)\end{array}$ & $p<0.001$ \\
\hline $\begin{array}{l}\text { "72 hour" peak gentamicin concentration }<4 \mu \mathrm{g} / \mathrm{ml} \\
(95 \% \mathrm{Cl})\end{array}$ & $\begin{array}{l}12 / 102 \\
12 \% \\
(6 \% \text { to } 20 \%)\end{array}$ & $\begin{array}{l}18 / 97 \\
19 \% \\
(11 \% \text { to } 28 \%)\end{array}$ & $p=0.24$ \\
\hline $\begin{array}{l}\text { Geometric mean "72 hour" peak gentamicin } \\
\text { concentration ( } \pm 1 \mathrm{SD})(\mu \mathrm{g} / \mathrm{ml})\end{array}$ & $\begin{array}{l}6.2 \\
(2.8,13.7)\end{array}$ & $\begin{array}{l}5.5 \\
(3.0,9.8)\end{array}$ & $p=0.19$ \\
\hline $\begin{array}{l}\text { "96 hour" trough gentamicin concentration } \\
\geqslant 2 \mu \mathrm{g} / \mathrm{ml} \text { in OD and MD groups (95\% Cl) }\end{array}$ & $\begin{array}{l}5 / 89 \\
6 \% \\
(2 \% \text { to } 13 \%)\end{array}$ & $\begin{array}{l}21 / 86 \\
24 \% \\
(16 \% \text { to } 35 \%)\end{array}$ & $p=0.001$ \\
\hline $\begin{array}{l}\text { "96 hour" trough gentamicin concentration } \\
\geqslant 1 \mu \mathrm{g} / \mathrm{ml} \text { in OD group and } \geqslant 2 \mu \mathrm{g} / \mathrm{ml} \mathrm{MD} \text { group } \\
(95 \% \mathrm{Cl})\end{array}$ & $\begin{array}{l}21 / 89 \\
24 \% \\
(15 \% \text { to } 34 \%)\end{array}$ & $\begin{array}{l}21 / 86 \\
24 \% \\
(16 \% \text { to } 35 \%)\end{array}$ & $p=0.99$ \\
\hline $\begin{array}{l}\text { Geometric mean "96 hour" trough gentamicin } \\
\text { concentration ( } \pm 1 \text { SD) }(\mu \mathrm{g} / \mathrm{ml})\end{array}$ & $\begin{array}{l}0.6 \\
(0.3,1.3)\end{array}$ & $\begin{array}{l}1.1 \\
(0.7,2.3)\end{array}$ & $p<0.001$ \\
\hline $\begin{array}{l}\text { Proportion with possible gentamicin nephrotoxicity } \\
(95 \% \mathrm{CI})\end{array}$ & $\begin{array}{l}1 / 89 \\
1 \% \\
(0 \% \text { to } 6 \%)\end{array}$ & $\begin{array}{l}2 / 85 \\
2 \% \\
(0 \% \text { to } 8 \%)\end{array}$ & $p=0.6$ \\
\hline $\begin{array}{l}\text { Mean fall in plasma creatinine }(\mu \mathrm{mol} / \mathrm{l}) \text { at "96 hours" } \\
(95 \% \mathrm{CI})\end{array}$ & 18 & $\begin{array}{l}11 \\
(5 \text { to } 17)\end{array}$ & $p=0.13$ \\
\hline
\end{tabular}


pre-dose gentamicin concentrations on the fourth day of treatment, are therefore very encouraging. Even if one accepts that lower trough concentrations are desirable with OD regimens, ${ }^{26}$ the OD regimen performed as well as the MD regimens.

It was our intention that any results from this trial could immediately be generalised to similar settings in resource poor countries. The study was performed on a government ward with average bed occupancy of over $100 \%$. We used commonly available, though suboptimal drug formulations, and did not change pragmatic fixed time dosing. In addition we included high risk groups (ignored in current international guidelines ${ }^{14}$ ) in the study population, testing an OD regimen that requires determination of age and weight (rather than gestation) only to decide on dosage in the newborn period. As 14\% of the sick infants admitted during the study period weighed less than $2 \mathrm{~kg}$, the predominant cause being prematurity (observation of the authors), and as over $40 \%$ were aged $\leqslant 7$ days we feel this level of complexity is warranted even in a developing country setting. It is therefore reassuring to know that, without the benefit of routine therapeutic drug monitoring to individually tailor treatment, the OD regimen performed well. There is also a lack of good data on the risks of gentamicin toxicity in resource poor countries. Once again our data are reassuring. The risk of possible nephrotoxicity seems low, and the limited data we collected on infants receiving prolonged therapy tends to support this conclusion. However, it should be remembered that approximately $2 \%$ of sick young infants thought to require parenteral antibiotics were excluded from the trial because of a grossly raised creatinine at admission (including three randomised but then excluded). In a setting unable to measure creatinine these children are likely to be at higher risk of unwitting gentamicin toxicity.

We therefore conclude, judged by pharmacological surrogates for clinical outcomes and in comparison with traditional multi-dose regimens, that our "two, four, six, eight" OD regime is a suitable regimen for infants up to 60 days of age when used as empiric, unmonitored therapy in resource poor countries. Adoption of such a regime is likely to reduce $\operatorname{costs}^{13}$ and importantly spare valuable nursing time. Changing local or national guidelines should however be accompanied by appropriate training. In this context it should be remembered that doses recommended in once daily regimes should not be given as an intravenous bolus. Intramuscular dosing is the preferred route unless reliable infusion devices are available. As even with a high initial dose, gentamicin concentrations were only moderate, future studies should consider the possibility of even higher dosing with two or even three day administration intervals.

\section{ACKNOWLEDGEMENTS}

This study is published with the permission of the Director of KEMRI. The authors would like to thank the nurses and project assistants on Ward 1 of Kilifi District Hospital for their invaluable help during the conduct of this study. Particular thanks are owed to Tom Oluoch who designed the patient entry/randomisation programme. Mike English (050563) and Kevin Marsh (031342) are supported through Wellcome Trust fellowships.

\section{Authors' affiliations}

M English, S Mohammed, A Ross, K Marsh, Centre for Geographic Medicine Research, Coast, KEMRI/Wellcome Trust Research Laboratories, PO Box 230, Kilifi, Kenya

S Ndirangu, G Kokwaro, Wellcome Trust Research Laboratories, Nairobi, Kenya

F Shann, Royal Children's Hospital, Melbourne, Australia

Financial support for this study was provided by the Wellcome Trust (UK)

\section{REFERENCES}

1 Chuck S, Raber S, Rodvold K, et al. National survey of extended-interval aminoglycoside dosing. Clin Infect Dis 2000;30:433-9.

2 Ali $M$, Goetz M. A meta-analysis of the relative efficacy and toxicity of single daily dosing versus multiple daily dosing of aminoglycosides. Clin Infect Dis 1997;24:796-809.

3 Barza M, loannidis J, Cappelleri J, et al. Single or multiple daily doses of aminoglycosides: a meta-analysis. BMJ 1996;312:338-45.

4 Bailey T, Little J, Littenburg B, et al. A meta-analysis of extended-interval dosing versus multiple daily dosing of aminoglycosides. Clin Infect Dis 1997;24:786-95.

5 Fisman D, Kaye K. Once daily dosing of aminoglycoside antibiotics. Infect Dis Clin North Am 2000;14:475-87.

6 Campbell H. Single or multiple daily doses of aminoglycosides. BMJ 1996;313:490.

7 Conroy S. Optimal dosing schedules with gentamicin are needed for premature neonates. BMJ 1998;317:204-5.

8 Miron D. Once daily dosing of gentamicin in infants and children. Pediatr Infect Dis J 2001;20:1169-73.

9 Agarwal G, Rastogi A, Pyati $S$, et al. Comparison of once daily versus twice daily gentamicin dosing regimens in infants $>$ or $=2500 \mathrm{~g}$. J Perinatol 2002;22:268-74.

10 Hayani K, Hatzopoulos F, Frank A, et al. Pharmacokinetics of once daily dosing of gentamicin in neonates. J Pediatr 1997;131:76-80.

11 de Alba-Romero C, Castillo E, Manzanares C, et al. Once daily gentamicin dosing in neonates. Pediatr Infect Dis J 1996;17:1 169-71.

12 Skopnik H, Wallraf R, Nies B, et al. Pharmacokinetics and antibacterial activity of daily gentamicin. Arch Dis Child 1992;67:57-61.

13 Thureen P, Reiter P, Gresores A, et al. Once versus twice daily gentamicin dosing in neonates greater than or equal to 34 weeks gestation: a costeffectiveness analysis. Pediatrics 1999;103:594-8

14 World Health Organisation. Management of the child with a serious infection or severe malnutrition. Geneva: World Health Organisation, 2000.

15 Edwards C, Low D, Bissenden J. Gentamicin dosage for the newborn. Lancet 1986;1:508-9.

16 Szefler S, Wynn R, Clarke D, et al. Relationship of gentamicin serum concentrations to gestational age in preterm and term neonates. J Pediatr 1980;97:312-15.

17 Mulhall A, De Louvois J, Hurley R. Incidence of potentially toxic concentrations of gentamicin in the neonate. Arch Dis Child 1983;58:897-900.

18 Assael B, Gianni V, Peneff A, et al. Gentamicin dosage in preterm and term neonates. Arch Dis Child 1977;52:883-6.

19 Isemann B, Kotagal U, Mashni S, et al. Optimal gentamicin therapy in preterm neonates includes loading doses and early monitoring. Ther Drug Monit 1996; 18:549-55

20 Ministry of Health, Government of Kenya. Clinical guidelines. Nairobi: Government of Kenya, 1994

21 Lacy M, Nicolau D, Nightingale C, et al. The pharmacodynamics of once daily aminoglycosides. Clin Infect Dis 1998;27:23-7.

22 McCracken G, Threlkeld N, Thomas M. Intravenous administration of kanamycin and gentamicin in newborn infants. Pediatrics 1977;60:463-6.

23 Rudd P, Hughes E, Placzek M, et al. Reference ranges for plasma creatinine during the first month of life. Arch Dis Child 1983;58:212-15.

24 Hui H, Macnab A. Reference data and formulae. In: Macnab A, Macrae D, Henning R, eds. Care of the critically ill child. London: Churchill Livingstone, 1999:601.

25 Parker S, Davey P. Once daily aminoglycoside dosing. Lancet 1993;341:346-7

26 Reeves DS, MacGowan AP. Once daily aminoglycoside dosing. Lancet 1993:341:895-6.

27 Bang A, Bang R, Baitule S, et al. Effect of home based care and management of sepsis on neonatal mortality: field trial in rural India. Lancet 1999;354:1955-61.

28 McCormack J, Jewesson P. A critical reevaluation of the therapeutic range of aminoglycosides. Clin Infect Dis 1992;14:320-9. 